\section{Action of Reserpine on Isolated Intestinal Muscle}

Certarn intermediates of the tricarboxylic acid cycle antagonize the reserpine inhibition of contractions induced by drugs of isolated guinea pig ileum ${ }^{1}$ (Table 1). We have observed that the most effective reserpine antagonists were those added as the free acids. These reduced the reaction of the bath-fluid to about $p H 5$. When the reaction was reduced to similar levels by the addition of small volumes of $0.2 \mathrm{~N}$ hydrochloric acid, antagonism to reserpine was also seen. This was less marked, however, than that following addition of the most effective metabolites, which included $\alpha$-ketoglutaric acid (1 mgm. per ml.) and cis-aconitic acid anhydride (1 mgm. per ml.). At a bath $p H$ of $7 \cdot 4$, no antagonism to reserpine was seen.

Hydrochloric acid produced a similar degree of antagonism to reserpine as did $1 \mathrm{mgm}$. per $\mathrm{ml}$. of DL-leucine, which was tested along with other aminoacids and intermediates of fat metabolism (Table 1). It was concluded that these compounds are effective by virtue only of their ability to increase the hydrogen ion concentration of the bath fluid. Sodium pyruvate (1 mgm. per ml.) and sodium fumarate (1 mgm. per ml.), previously found to be inactive, were rendered active by reduction of the bath $p H$ to 5 with hydrochloric acid. Furchgott and Wales ${ }^{2}$ have suggested, on the basis of experiments on isolated rabbit intestinal muscle, that succinate, $\alpha$-ketoglutarate and fumarate are more effective at lower bath $p H$ values as sources of energy for the activity of this tissue.

Using Locke's solution, isolated rabbit duodenum showed ${ }^{3}$ a reduction of tone and depression of spontaneous activity following addition of $10 \mu \mathrm{gm}$. per $\mathrm{ml}$. of reserpine, which reduced the bath $p \mathrm{H}$ from $7 \cdot 4$ to $6 \cdot 9$. When the $p H$ change of the bath-fluid which follows addition of reserpine (dissolved in ascorbic acid/sodium ascorbate mixture) is prevented by the use of Krebs-Henseleit solution ${ }^{4}$, a stimulant action precedes the reduction in tone and rhythmic activity (Fig. 1). This effect is prevented by the prior addition to the bath of $1 \mu \mathrm{gm}$. per $\mathrm{ml}$. of atropine sulphate or $1 \mu \mathrm{gm}$. per ml. of hexamethonium bromide but not by $2 \mu \mathrm{gm}$. per ml. of 2 -brom D-lysergic acid diethylamide (BOL 148). These observations on rabbit gut support the findings of Plummer and his colleagues on dog gut in situ ${ }^{5}$.

Table 1. ACTIVTY OF COMPOUNDS TESTED FOR ANTAGONISM TO THE ACTION OF RESERPINE ON GUINEA PIG ILEUM Effect

Intermediates of

(a) Fat metabolism 3-Hydroxybutyric acid

(b) Protein propionate rotein metabolism L-Glutamic acid DL-a-Alanine

(c) Carbohydrate metabolism Glucose-1-phosphate Glucose-1-phosphate Gructose-1,6-diphosphat 3-Phosphoglyceric acid Sodium pyruvate Sodium succinat Sorium fumbrat Citric acid cis-Aconitic acid anhydride isoCitric acid $\alpha$-Ketoglutaric acid Malic acid Maleic acid

Oxaloacetic acid

Alone With hydrochloric acid

0 represents no activity

+ represents activity equal to that of hydrochloric acid

++ represents activity greater than that of hydrochloric acid

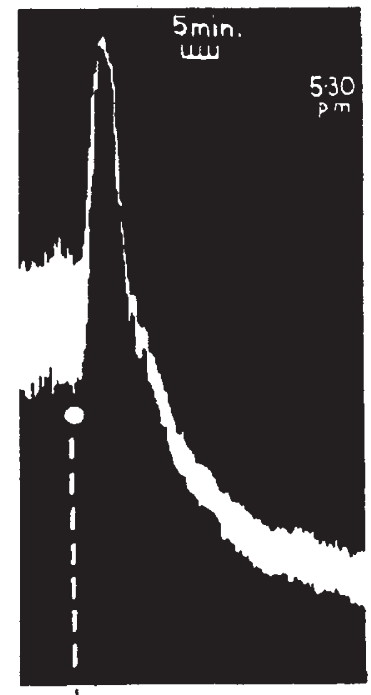

$\stackrel{1}{R}$

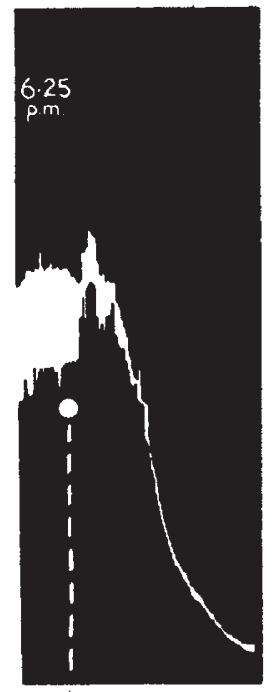

$\boldsymbol{R}+\boldsymbol{A}$
Fig. 1. Isolated rabbit duodenum suspended in $5 \mathrm{ml}$. KrebsHenseleit solution. At $R, 10 \mu \mathrm{gm}$. per ml. reserpine added at $\boldsymbol{R}+\boldsymbol{A}, 1 \mu \mathrm{gm}$. per ml. atropine sulphate

We wish to thank Dr. C. D. Falconer, of Cibs Laboratories, Ltd., for generous supplies of reserpine.

C. N. Grulis

J. J. LEWIS

Dept. of Materia Medica and Therapeutics, University,

Glasgow, W.2. Jan. 18.

${ }^{1}$ Gillis, C. N., and Lewis, J. J., Nature, 178, 859 (1956).

- Furchgott, R. F., and Wales, M. R., Amer. J. Physiol., 169, 326 (1952).

s Gillis, C. N., and Lewis, J. J., J. Pharm. Pharmacol., 8, 606 (1956). - Krebs, H. A., and Henseleit, K., Z. physiol. Chem., 210, 33 (1932).

- Plummer, A. J., Barret, W. E., and Rutledge, R., Amer. J. Dig. Dis., 22, 337 (1955).

\section{Slow Freezing of Carp Muscle and Inosinic Acid Formation}

Ix has been noticed that when fresh muscles are frozen at very low temperature, for example, by sudden immersion in liquid propane or in liquid nitrogen, there is no significant change found in the amounts of adenosine triphosphate or creatine phosphate ${ }^{1}$. We have observed ${ }^{2}$ the changes which take place in fresh muscle of earp during storage in an ice chest at $-8^{\circ} \mathrm{C}$. Under these conditions, the material was frozen slowly and it was found that the amounts of adenosine triphosphate and creatine phosphate decrease very rapidly, and those of compounds such as inosine monophosphate increase greatly. In the present work, an attempt has been made to observe the formation of inosine monophosphate during the course of slow freezing of carp muscle.

Experiments were carried out on dorsal muscle of carp. $1 \mathrm{gm}$. of fresh muscle was solidified by freezing by storage at $-8^{\circ} \mathrm{C}$. for $5 \mathrm{hr}$. The frozen muscle was homogenized with $20 \mathrm{ml}$. of 4 per cent perchloric acid solution at low temperature and the perchloric acid extract was filtered and separated by ionexchange chromatogxaphy.

The degree of separation and optical densities of separated nucleotides are shown in Fig. 1. For each 